\title{
El oficio de partera entre los siglos XV al XVIII. Fuentes documentales para su estudio ${ }^{1}$
}

\section{The Office of a midwife from the 15th to the 18th centuries. Documentary sources for study}

\section{O Office de uma parteira do século XV ao século XVIII. Fontes documentais para estudo}

\begin{abstract}
Manuel Jesús García Martínez
Enfermero y Matrona. Dr. en Antropología Social y Cultural. Prof. Asociado. Facultad de Enfermería, Fisioterapia y Podología. Universidad de Sevilla.

Cómo citar este artículo en edición digital: García Martínez, M.J. (2012) El oficio de partera entre los siglos XV al XVIII. Fuentes documentales para su estudio.Cultura de los Cuidados. (Edición digital) 16, 32. Disponible en: http://dx.doi.org/10.7184/ cuid.2012.32.11

Correspondencia: Manuel Jesús García Martínez. C/ Bailén, n.88.41500 - Alcalá de Guadaíra (Sevilla). Email: mjgm10@ arrakis.es (teléf:955681490 / 619902546)) Recibido: 21/11/2011 - Aceptado: 13/02/2012
\end{abstract}

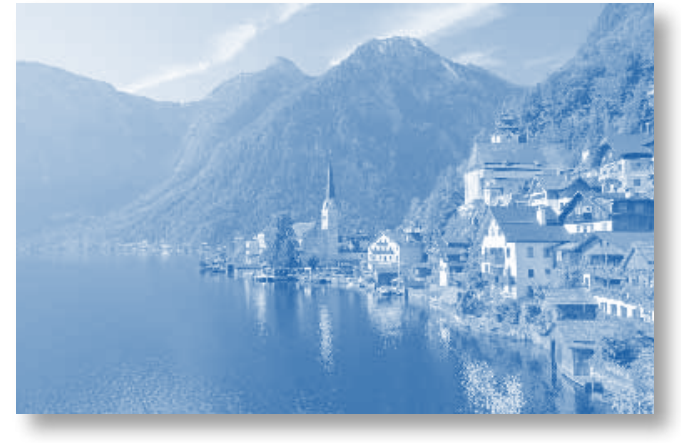

ABSTRACT

The midwife has traditionally been developing his practice over the centuries in the field of reproductive health of women developing care, teaching, expertise, religious functions and as an adviser in this matter. Despite being an occupation or trade as old as humanity itself, as recorded is in countless testimonies written and iconographic, are relatively rare research work carried out on this profession in late medieval and early modern age. We in- tend as a central objective of this paper show and analyze some documentary sources dated between the 15th and 18th centuries that provide a rich information about the daily work of these professionals, since its formation until the tasks that were usually: meet delivery, care during pregnancy and puerperium, give advice to women in all matters relating to their sexuality, even engaged in practices not legal as it was the practice of abortion, all of which made him a frequent object of suspicion by the Court of the Holy Office of the Inquisition. are three sources that are analysed: a public letter from birth, a pastoral visit, specifically made to the Sevillian town of Mairena del Alcor, and a process or auto de Fé against a Mexican midwife.

Key words: midwife; documentary sources; visit pastoral; Auto de Fé; public letter of childbirth.

\footnotetext{
${ }^{1}$ Texto de la ponencia expuesta por el autor en la Mesa Redonda titulada: "Historia y Cultura de los Cuidados", dentro del III Simposio Iberoamericano de Historia de la Enfermería, XII Congreso Nacional y VII Congreso Internacional de Historia de la Enfermería y VII Jornadas Internacionales de Cultura de los Cuidados, organizados por la Universidad de Alicante durante los dias 24-26 de noviembre de 2011.
} 


\section{RESUMO}

A parteira tradicionalmente vem desenvolvendo sua prática ao longo dos séculos no campo da saúde reprodutiva das mulheres, desenvolvimento de cuidados, ensino, especialização, funções religiosas e como um conselheiro nesta matéria. Apesar de ser uma ocupação ou comércio tão velho quanto a humanidade propriamente dito, como registrado é em inúmeros testemunhos escritos e iconográficos, são trabalhos de investigação relativamente rara efectuados sobre esta profissão na idade moderna medieval e início tardia. Temos a intenção como um objectivo central deste show de papel e analisar algumas fontes documentais datados entre os séculos XV e XVIII que fornecem uma ricas informações sobre o trabalho diário destes profissionais, desde a sua formação até as tarefas que eram geralmente: atender a entrega, cuidados durante a gravidez e puerpério, aconselhar as mulheres em todas as questões relacionadas com a sua sexualidade, ainda envolvidos em práticas não é legais como era a prática do aborto, tudo o que fez de um objeto freqüente de suspeita pelo Tribunal do Santo Ofício da Inquisição. são três fontes que são analisadas: uma carta pública de luz, uma visita pastoral, feita especificamente para o sevilhano cidade de Mairena del Alcor e um processo ou autode-Fé contra uma parteira mexicana.

Palavras-chave: parteira; fontes documentais; visita pastoral; Auto-de-Fé; carta pública do parto.

\section{RESUMEN}

La partera tradicionalmente ha venido desarrollando su ejercicio profesional a lo largo de los siglos en el campo de la salud reproductiva de la mujer desarrollando las funcio- nes asistencial, docente, de peritaje, religiosa y como asesora en dicha materia. A pesar de ser una ocupación u oficio tan antiguo como la humanidad misma, como queda constancia en innumerables testimonios escritos e iconográficos, son relativamente escasos los trabajos de investigación llevados a cabo sobre esta profesión a finales de la Edad Media y principios de la Edad Moderna.

Nos proponemos como objetivo central del presente trabajo mostrar y analizar algunas fuentes documentales fechadas entre los siglos XV y XVIII que aportan un rica información sobre el trabajo diario de estas profesionales, desde su formación hasta las tareas que realizaban habitualmente: atender el parto, prestar cuidados durante el embarazo y puerperio, aconsejar a la mujer en todo lo relativo a su sexualidad, incluso llevando a cabo prácticas no legales como era la práctica del aborto, todo lo cual le hacían con frecuencia objeto de sospecha por parte del Tribunal del Santo Oficio de la Inquisición.

Son tres las fuentes que se analizan: una carta pública de parto, una visita pastoral, concretamente la efectuada a la localidad sevillana de Mairena del Alcor, y un proceso o auto de fe contra una partera mexicana.

Palabras clave: partera; fuentes documentales; visita pastoral; auto de fe; carta pública de parto.

\section{INTRODUCCIÓN}

El hecho del cuidar, de administrar cuidados se remonta al origen de los tiempos. Si se trata del hecho del nacimiento y las personas que lo llevaban a cabo, mujeres tradicionalmente, las matronas o parteras, son abundantes los testimonios conservados que lo atestiguan, recogidos en las fuentes documentales, 
escritas e iconográficas, o de cualquier otra índole, conservadas en archivos, bibliotecas, museos y otras instituciones.

La partera tradicionalmente ha venido desarrollando su ejercicio profesional a lo largo de los siglos en el campo de la salud reproductiva de la mujer desarrollando funciones asistencial, atendiendo el embarazo, parto y puerperio; docente, formando a otras parteras; de peritaje, interviniendo en procesos judiciales dando fe pública de su trabajo; religiosa, administrando el llamado "bautismo de urgencia" en aquellos casos en que se preveía una muerte inminente del recién nacido o del nonato, $y$, por último, la función de consejera o asesora en materia sexual u obstétrico-ginecológica.

A pesar de ser una ocupación u oficio tan antiguo como la humanidad misma, como queda constancia documental, son relativamente escasos los trabajos de investigación llevados a cabo sobre esta profesión y las profesionales que la ejercen a finales de la Edad Media y durante la Edad Moderna, en comparación con los que vienen realizándose en el campo de la historia del cuidado enfermero en general.

Nos proponemos como objetivo central del presente trabajo mostrar y analizar algunas fuentes documentales fechadas entre los siglos XV y XVIII que aportan un rica información sobre el trabajo diario de estas profesionales, las parteras, permitiéndonos conocer su formación, estatus social y económico, las funciones y tareas que desarrollaban habitualmente, en definitiva el contexto socioprofesional en donde se desenvolvía. Todas estas fuentes documentales tienen en común una protagonista: la partera.

\section{MATERIAL Y MÉTODO}

Se exponen y analizan tres documentos de distinta índole, localizados en diversos archi- vos de la geografía nacional, fechados en los siglos XV, XVII y XVIII: un auto o proceso de fe seguido contra la partera Petrona de Fuentes en México, año de 1709; una carta pública de parto, solicitada por Isabel de la Cavallería en Zaragoza en 1490 y una visita pastoral realizada a la localidad de Mairena del Alcor (Sevilla) en 1694, en la que se interroga a la partera Josefa de Castillejo. Una vez localizados estos documentos se ha procedido a su transcripción y análisis, extrayéndose aquella información que arroja luz sobre el trabajo de las parteras.

La identificación de estos documentos es la siguiente:

1. Proceso de fe llevado a cabo en el año 1709 en México contra la partera Petrona de Fuentes.

Fecha: 1709-1715

Archivo: Archivo Histórico Nacional (Madrid)

Signatura: Inquisición, 1733. Exp. 34

2. Carta pública de parto de Isabel de la Cavallería, hija de Alfonso de la Cavallería y viuda de Pedro de Francia, que dio a luz un varón.

Fecha: carta de 10 de enero de 1490

Archivo: Archivo Histórico de Protocolos Notariales de Zaragoza

Signatura: Protocolo de Domingo Cuerla, año de 1490, ff. 2v-4v.

3. Visita pastoral realizada a la localidad sevillana de Mairena del Alcor en el año 1694. Fecha: 1694

Archivo: Archivo General del Arzobispado de Sevilla

Signatura: Libro de Visita Pastoral. Localidad: Mairena del Alcor (Sevilla) 


\section{RESULTADOS}

\section{Los procesos o autos de fe como fuentes de} información para la historia de la partera.

Sobre el trabajo de la partera en los siglos medievales y Edad Moderna existe documentación variada que muestra el férreo control a que eran sometidas estas profesionales por parte de las autoridades eclesiásticas, como los libros de visitas pastorales o los autos de fe (1). Pero, ¿qué eran los procesos o autos de fe y qué información arrojan que nos pueda ser útil para el conocimiento de la histora de la matrona?

El auto o "acto" de fe era una ceremonia pública, celebrada con gran pompa y solemnidad, con asistencia de Inquisidores, Familiares del Santo Oficio, eclesiásticos, órdenes religiosas y las personalidades más destacadas del lugar, reunidos generalmente en la plaza pública de las ciudades para escuchar el veredicto de las sentencias individuales dictadas contra los reos de la Inquisición. Su origen se remonta a la Inquisición Medieval y su momento de auge se sitúa entre los siglos XVI y XVII. En los inicios de la Inquisición Moderna, los autos de fe no estaban concebidos para atraer a muchos espectadores: era un simple rito religioso en que se hacían las abjuraciones y reconciliaciones y se comunicaba la pena impuesta a cada reo (2). Por tanto, la misión del Tribunal del Santo Oficio era la defensa de la fe y la moral de la Iglesia católica, mediante la persecusión de los delitos que atentaran contra una u otra.

Las mujeres acusadas de hechicería, como el caso de la partera que presentamos, confesaban ante el Tribunal que el motivo que les movía no era el de la veneración al demonio sino el de buscar un complemento económico a su trabajo; por tanto, su perfil era el de uma mujer entre treinta y cincuenta años o más, de origen generalmente modesto en el que la práctica hechicera representaba un modo de sustento apreciable (3).

El caso que presentamos es el proceso de fe seguido contra una partera, natural de Cuatitlán, viuda de edad imprecisa ("dize ser de más de 50 años y pareze de más de 60 ") y que fue juzgada por el Tribunal de la Inquisicón de México en el año 1709 acusada de "supersticiosa embustera".

Un análisis exhaustivo de todo el proceso, aunque interesante, escaparía a la finalidad del presente trabajo debido a la limitación espacial; no obstante, deseamos destacar la información que este tipo de proceso penal aporta y que puede resultar relevante para el conocimiento del contexto socioprofesional en que se movía una partera de finales del siglo XVII y comienzos del XVIII.

En relación a las fases del proceso penal inquisitivo del Tribunal del Santo Oficio (2), y de manera resumida, destacamos las siguientes:

$1 .^{a}$ Fase preprocesal, en la que se daba inicio al proceso (por acusación, por denuncia, por Inquisición General o por Inquisición Especial) y se ponían en práctica las medidas cautelares (citación o detención y confiscación de bienes).

2. ${ }^{a}$ Fase inquisitiva del proceso, que en su etapa inquisitiva propiamente dicha constaba del interrogatorio inicial, sin tormento, y la acusación formal.

3. ${ }^{a}$ Fase judicial del proceso, dividida en dos etapas: la etapa probatoria (prueba de testigos, confesión de culpabilidad y "question de tormento") y la etapa de conclusión del proceso, distinguiéndose en ésta dos momentos: la revisión del proceso y la "compurgación" o refutación de indicios inculpadores sobre una persona.

A la pregunta de ¿qué información aporta un proceso de fe sobre las parteras?, y adentrándonos en la documentación generada por 
el proceso o auto de fe seguido contra Petrona de Fuentes, recogemos los siguientes datos: su nombre: "Petrona de Fuentes"; lugar de nacimiento o nacionalidad: "Natural de Cuatitlán"; el lugar donde vive: "México"; su estado civil: "viuda"; oficio que ejerce: "partera o matrona"; la fecha y lugar en donde ha ejercido el oficio: : "vezina de México"; su edad: "dize ser de más de 50 años y pareze de más de 60"; el motivo o causa del enjuiciamiento: "por supersticiosa y embustera"; si los testigos acuden por motus propio o recomendada por alguien: "por su confesor". A esta información habría que añadirle la obtenida por los interrogatorios de los testigos o denunciantes, que resaltaban aspectos de la denunciada como sus relaciones sociales -amigas, vecinas...-, la formación en materias como la religión o hechicería y otras ciencias ocultas y perseguidas, el estatus socioeconómico de la denunciada, que en el caso que nos ocupa era de pobreza, o las técnicas que la partera empleaba, el empleo de "varitas de virtud" o amuletos, todo ello muy interesante desde el punto de vista de la historia y de la antropología.

Finalizamos este caso de auto de fe con la sentencia emitida por el Tribunal, consistente en prisión y embargo de los bienes de la partera acusada:

"Calificáronse los dichos y echos antezedentes en 4 de Julio de 709 y la Censura es que por ellos se constituía rea del Santo Ofizio por embustera supertiçiosa con sauor de herejía sortílega abusiua de la Santa Cruz, Santas Palabras y agua bendita, sospechosa de nigromantia, y por todo la jusgan sospechosa leuemente en la fee con pacto inplícito con el demonio.

Con vista de todo se botó a prisión en cárseles secretas con embargo de vienes en 7 de Septiembre de 709 que se executó en 13 de él, pero no se allaron vienes algunos". (4)

\section{La cartas públicas de parto.}

Otra interesante fuente documental para el estudio del oficio/profesión de la partera a lo largo de la historia son las "cartas públicas de parto" (5), actas levantadas por los notarios en donde se da fe del desarrollo de un parto. Generalmente estos documentos eran solicitadas por mujeres pertenecientes a las clases sociales elevadas, que habían enviudado y que deseaban dejar una prueba de la legitimidad del recién nacido. El notario llegaba a una precisión descriptiva tal que nos permite conocer minuciosamente el desenlace del parto, desde los primeros síntomas -rotura del saco amniótico, inicio de la salida del feto hasta el alumbramiento o salida de la placenta-. Y, por supuesto, y con la finalidad de evitar fraude, el mismo notario se encargaba de comprobar $y$ registrar personalmente tanto a la futura madre como a las parteras que la asisten de que no llevaban oculto niño alguno.

Exponemos en las líneas que siguen una de estas cartas o actas, levantada por el notario Domingo de Cuerla el 10 de enero de 1490, localizada en el Archivo Histórico de Protocolos Notariales de Zaragoza. El notario confirma que Isabel de la Cavallería, hija de Alfonso de la Cavallería y viuda de Pedro de Francia, señor de Bureta, da a luz a un varón, siendo atendida por una experta matrona o madrina llamada Catalina de Cutanda, viuda de Gabriel de Salinas. Veamos seguidamente parte de la información que contiene esta carta pública de parto.

El parto sucede el día 10 de enero de 1490, entre las diez y las once de la mañana, en las habitaciones altas de la casa del Sr. Martín de Burueta, abiertas las ventanas y encendidas algunas "candelas vendezidas". Dos mujeres sostenían a la parturienta por "debaxo de los sobacos", mientras gritaba de dolor por la in- 
minente salida del feto. Se hallaban presentes el notario, D. Domingo de Cuerla, y otros testigos requeridos por la dicha señora Isabel de la Cavallería, además de otra partera o madrina, llamada Aína de Medina, a todos los cuales el notario palpó con sus manos "sus cuerpos y entre sus piernas, y levantadas las faldas de sus ropas fasta la camisa por veyer y reconocer si con alguna cautela o enganyo las madrinas consigo trayrían alguna criatura [...]" (5). Tras ponerse las dos parteras de rodilla en tierra y jurar no proceder con engaño alguno, comienza el parto. Señala el notario que en el vientre de la parturienta se habían colocado algunas reliquias y en la habitación, como queda dicho, "muchas candelas vendezidas que allí stavan ardiendo", estando de rodillas una de las madrinas y la otra, Catalina, con un paño en sus rodillas para recibir a la criatura. Se había colocado un "bacín de allaton" entre las piernas de la parturienta para recoger la sangre y líquido amniótico y al poco tiempo "sallió y parió de su cuerpo una criatura toda moxada, los ojos cerrados, la qual craitura recibió en sus manos [...]". Posteriormente, la dicha madrina Salinas procede a extraer la placenta o "lecho donde la dita craitura se havía nodrido del cuerpo de la dita Ysabel de la Cavallería, el qual lecho viemos yo, dito notario, e testimonios cayer dentro del dito bacín con mucha sangre que allí stava [...]". El notario continúa dando detalles del parto y se fija en el sexo del recién nacido, un varón, no había dudas: “[...] la dita criatura nascida era ombre, como tuviese todos los miembros masculinos que los ombres tienen, y senyaladament su miembro y companyones, alias vulgarment clamados pixa y cogones" (5).

Relato, como puede comprobarse, de extraordinario valor antropológico e histórico para la profesión de matrona, pues nos describe desde la postura de parir que adopta la futu-

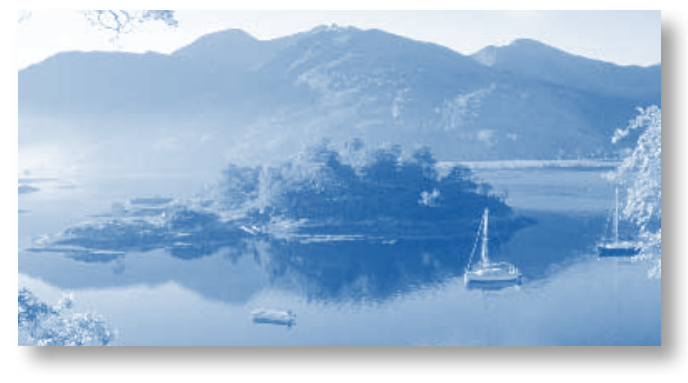

ra madre hasta los materiales y utensilios que las parteras empleaban, además de las reliquias y otros elementos simbólicos empleados para el buen desarrollo del parto.

\section{Las visitas pastorales.}

Continuando con las fuentes documentales para el estudio de la historia de las matronas, creemos igualmente de interés otro tipo de documentación, generada por las visitas pastorales. Los libros de visita pastoral recogen las actas con información referida a distintas instituciones -hospitales, iglesias...- de las localidades inspeccionadas por el Visitador del Arzobispado, incluyéndose en ella la relativa al ejercicio profesional de maestros de primeras letras, médicos y parteras o matronas (7).

¿Qué información aportan estos libros? Sucintamente, referimos la siguiente:

1. Si había matrona en la localidad visitada.

2. Su titulación.

3. Edad de la partera, años de ejercicio profesional y su estado civil.

4. Si la matrona estaba convenientemente instruida para administrar el denominado "bautismo de urgencia", además de su moralidad y costumbres.

5. El número de vecinos de la localidad, por lo que podemos obtener la carga de trabajo de estas profesionales.

6. Otros datos sobre las matronas. Por ejemplo, si eran diestras o hábiles en su ejercicio, nivel intelectual, su relación con otros profesionales, etc. 
Hacemos referencia seguidamente a una visita pastoral efectuada a la localidad sevillana de Mairena del Alcor en el año 1694, cuyo acta se conserva en el Archivo General del Arzobispado de Sevilla. Entre otra información sobre las parteras, se recoge que en ese pueblo ejercía una matrona o partera llamada Josefa de Castillejo, que exhibió al señor visitador una Carta de Examen de su ejercicio expedida por el corregidor D. Francisco Arévalo y Aceuedo el dos de dieciembre del año 1665 y que "saue vien la forma del Baptismo y puede seguramente bauptizar en caso de necesidad" (6). En relación a su vida social y aficiones, se dice que "es de buenas costumbres", que tiene una edad de 67 años y que tenía una gran experiencia en el desarrollo de su ejercicio, exactamente 32 años.

\section{CONCLUSIONES}

Las fuentes documentales generadas por las parteras en el ejercicio de sus tareas asistenciales y de peritaje entre los siglos XV y XVIII nos permiten hoy conocer muchos aspectos de su trabajo diario: su formación, sus funciones, sus aspiraciones y limitaciones profesionales...

Encontramos fuentes documentales muy variadas: desde protocolos notariales hasta procesos de fe, visitas pastorales, manuales para su instrucción, tratados científicos, procesos judiciales y disposiciones legales, sin olvidar las fuentes iconográficas.

El conocimiento de estas fuentes permitirá al investigador poner en marcha distintos proyectos de investigación que arrojen luz sobre el oficio de la partera o matrona y las mujeres que lo ejercían.

En la actualidad, el número y la calidad de fuentes existentes permiten augurar buenos resultados para la puesta en marcha de estos proyectos de investigación.

\section{BIBLIOGRAFÍA}

(1) García Martínez, Manuel J.; García Martínez, Antonio C. "Documentos para la historia de las matronas en América: El proceso de fe contra Juana Prudencia Echavarría. Lima, 1778”. Híades. Revista de Historia de la Enfermería. Alcalá de Guadaíra (Sevilla), 2008, n.o $10,1007-1044$

(2) http://www.gabrielbernat.es/espana/inquisicion/ie/ proc/autodefe/autodefe.html

(3) Boeglin, Michel (2006), Inquisición y Contrarreforma. El Tribunal del Santo Oficio de Sevilla (1560-1700). Ediciones Espuela de Plata, Sevilla, p. 187.

(5) García Herrero, María del C., "Administrar del parto y recibir la criatura”. Aragón en la Edad Media, 1989, n. ${ }^{\circ} 8,283-292$.

(7) García Martínez, Antonio C.; García Martínez, Manuel J.; Valle Racero, Juan I. (1994) "Registro y control de las Matronas por la Iglesia hispalense. (La imagen de la Matrona a través de los Libros de Visitas Pastorales del Arzobispado de Sevilla, siglos XVII y XVIII)”. Híades. Revista de Historia de la Enfermería. Alcalá de Guadaíra (Sevilla). N. ${ }^{\circ}$ 1, 13-33.

\section{FUENTES}

(4) Documento: Proceso de fe seguido en México en el año 1709 contra la partera Petrona de Fuentes, partera, natural de Guautitlán (México), por hechicería y supersticiones. Archivo: Archivo Histórico Nacional (Madrid). Signatura: Inquisición, 1733. Exp. 34.

(5) Documento: Carta de parto de Isabel de la Cavallería, hija de Alfonso de la Cavallería y viuda de Pedro de Francia, que dio a luz un varón. Fecha: Carta de 10 de enero de 1490. Archivo: Archivo Histórico de Protocolos Notariales de Zaragoza Signatura: Protocolo de Domingo Cuerla, año de 1490, ff. 2v-4v.

(6) Documento: Visita pastoral realizada a la localidad sevillana de Mairena del Alcor en el año 1694. Archivo: Archivo General del Arzobispado de Sevilla. Signatura: Libro de Visita Pastoral. Año 1694. Localidad: Mairena del Alcor (Sevilla). 


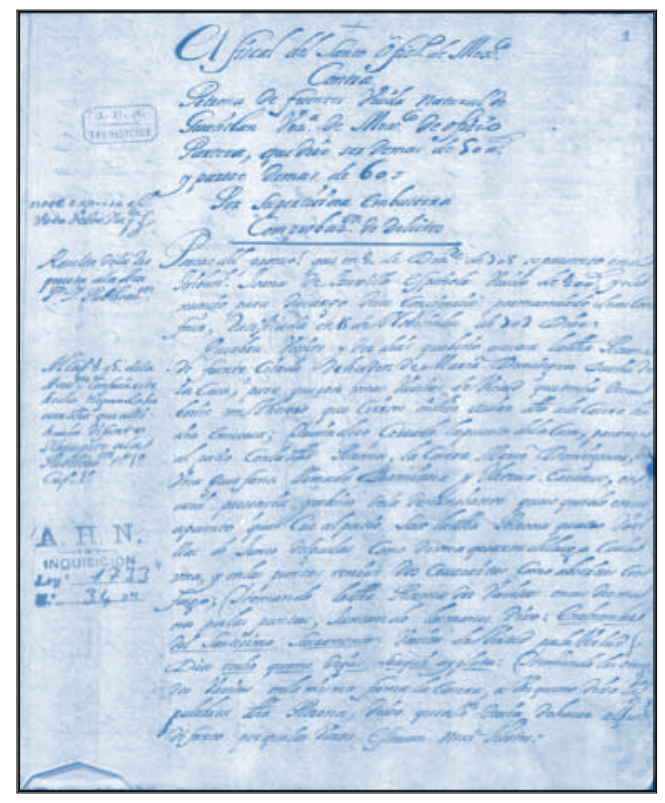

Ilustración 1. Proceso de fe llevado a cabo en el año 1709 en México contra la partera Petrona de Fuentes. Archivo Histórico Nacional (Madrid).

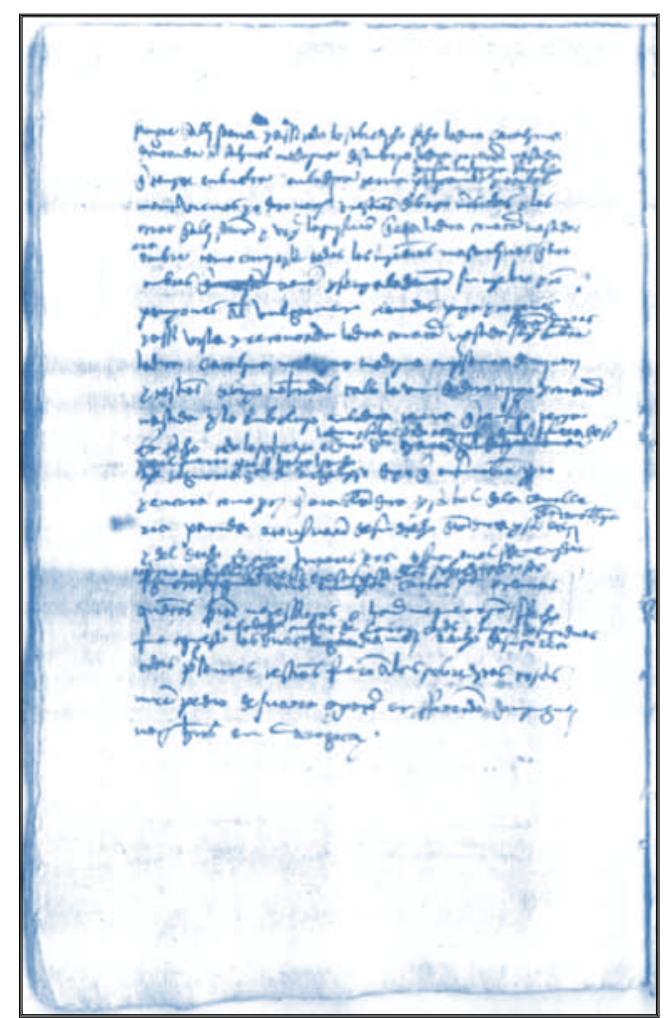

Ilustración 2. Carta pública de parto de Isabel de la Cavallería, que dio a luz un varón el 10 de enero de 1490. Archivo Histórico de Protocolos de Zaragoza.

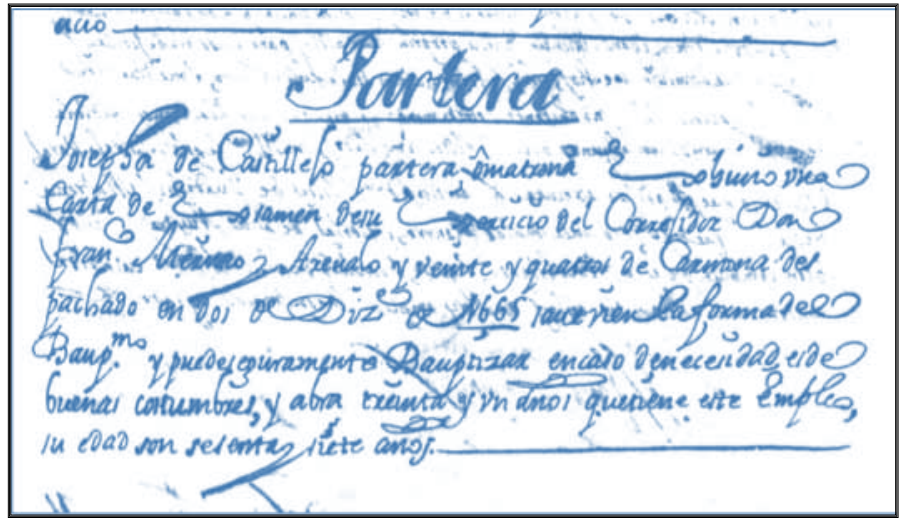

Ilustración 3. Visita pastoral realizada a la localidad sevillana de Mairena del Alcor en el año 1694. Archivo General del Arzobispado de Sevilla. 